\title{
An Approach to Equivalent Circuit Modelling of Inverted Organic Solar Cells
}

\author{
Nazmul Hossain"1, Sayantan Das' ${ }^{2}$, Terry L. Alford ${ }^{3}$ \\ ${ }^{1}$ Department of Electrical Engineering, Arizona State University, Tempe, Arizona, USA \\ ${ }^{2}$ School of Engineering of Matter, Transport and Energy, Arizona State University, Tempe, Arizona, USA \\ ${ }^{3}$ School of Engineering of Matter, Transport and Energy, and Department of Electrical Engineering, Arizona \\ State University, Tempe, Arizona, USA \\ Email: nhossai1@asu.edu, sdas30@asu.edu,TA@asu.edu
}

Received 4 March 2016; accepted 5 April 2016; published 8 June 2016

Copyright (C) 2016 by authors and Scientific Research Publishing Inc.

This work is licensed under the Creative Commons Attribution International License (CC BY).

http://creativecommons.org/licenses/by/4.0/

(c) (i) Open Access

\section{Abstract}

A low temperature sol-gel process was used to fabricate zinc-oxide and yttrium-doped zinc oxide layers. These zinc-oxide and yttrium-doped $\mathrm{ZnO}$ films were used as electron transport layers in conjunction with $\mathrm{P}_{3} \mathrm{HT}$ and $\mathrm{PC}_{16} \mathrm{BM}$ type solar cells. It was demonstrated that annealing and doping of electron transport layer influenced the overall organic solar cells performance. Anneals of $\sim$ $150^{\circ} \mathrm{C}$ provided the highest device performance. Compared to the undoped zinc oxide, the device with yttrium doped zinc oxide layers showed improved efficiency by about $30 \%$. Furthermore an equivalent circuit was proposed to understand the connection between the electrical and optical characteristics of the device. Comparisons between the simulated and experimental current-voltage (I-V) curves displayed only a $1.2 \%$ variation between the curves. Clearly, our experimental and simulated studies provide new insight on the equivalent circuit models for inverted organic solar cells and further improvement on photovoltaic efficiency.

\section{Keywords}

Inverted Organic Solar Cell, Equivalent Circuit, Fill-Factor, P3HT/PCBM, ETL, Yttrium-Doped ZnO

\section{Introduction}

The economic prosperity and the technological development are the key challenges for the world herself and energy plays the most important roles [1]. In today's world, fossil fuels (gas, coal, oil, etc.) are used extensively for cooling-heating, cooking and operating industrial as well as home appliances [2]. But, this energy sources are offensive to the environment as they produce huge carbon-dioxide $\left(\mathrm{CO}_{2}\right)$ during the burning period which 
causes to deplete the ozone layer at atmosphere that influences the green house effects more. It is also responsible for global warming [3]. Since the late $19^{\text {th }}$ century, the global mean surface temperature and the global sea level have increased by $0.3^{\circ} \mathrm{C}-0.6^{\circ} \mathrm{C}$ and $10-25 \mathrm{~cm}$, respectively [4]. These changes have already increased the number of natural disasters and are likely to have devastating effects for human and other life forms all around the world [5].

In the recent years, the scientists have given more eyes to the solar energy to handle the energy shortage issues all over the world [6]. To this point, organic solar cells (OSCs) are one of the promising solutions [7]-[10]. In OSCs, a phase-separated (BHJ) nanostructure is formed from a blend of fullerene derivative [6,6]-phenyl-C61 butyric acid methyl ester $\left(\mathrm{PC}_{61} \mathrm{BM}\right)$ and regioregular poly(3-hexylthiophene) $\left(\mathrm{P}_{3} \mathrm{HT}\right)$. As the exciton has only a certain lifetime before it collapses (where the electron recombines with the hole), the characteristic distance between an exciton generation site and a donor/acceptor interface must be on order of $5-10 \mathrm{~nm}$. At the same time, the photons need to traverse a certain thickness of active layer, often on the order of $100 \mathrm{~nm}$, in order for most of them to be absorbed. The blend of P3HT and PCBM offers a large interfacial area for efficient exciton dissociation [10]. Recently, $\mathrm{P}_{3} \mathrm{HT}: \mathrm{PC}_{61} \mathrm{BM}$ based OSC devices were fabricated and characterized by Guo et al. to use it for space applications [11]. These devices were tested under AM0 (air mass zero) illumination. Due to the molecular nature of these organic materials, the manufacturing processes of OSCs are relatively inexpensive. They are easy to fabricate as flexible large area sheets. However, several obstacles must be overcome in order to make them commercially available. One of these obstacles is that OSCs have lower efficiency and lifetimes compared to commercially available Si solar cells [12]-[16].

In case of OSC devices, the short circuit current $\left(\mathrm{J}_{\mathrm{SC}}\right)$, open circuit voltage $\left(V_{O C}\right)$, and fill factor $(\mathrm{FF})$ are widely dependent on the energy level alignment at the interfaces between each layer [17]. For example, application of interfacial layers in OSCs results enhanced $V_{O C}$ [17]-[20]. On the other hand, the use of non-ohmic contacts in between electrode and the organic layers may result in a lower $V_{O C}$. Moreover, the charge collection efficiency is also increased by the addition of interfacial layers. It also decreases the interfacial contact resistance. As a result, smaller series resistance $\left(R_{S}\right)$ and larger shunt resistance $\left(R_{S H}\right)$ are achieved [17] [21] [22].

In one of our previous studies, we fabricated organic solar cell based on a composite of fullerene derivative [6,6]-phenyl-C61 butyric acid methyl ester (PCBM) and regioregular poly (3-hexylthiophene) (P3HT) with an added interfacial layer of AgOx in between the PEDOT:PSS layer and the ITO layer. We investigated the properties of OSC devices with an added AgOx interfacial layer between the PEDOT:PSS and ITO and developed a model that best describes this device. The AgOx and PEDOT:PSS layers form a composite hole transport layer. It increases the fill-factor (FF), power conversion efficiency (PCE) and reduces the physical contact of PEDOT: PSS with ITO. Incorporation of the AgOx interfacial layer shows an increase in fill factor (by 33\%) and power conversion efficiency (by 28\%). The interfacial modification also results in improved shunt resistances suggesting lesser charge recombination due to cascading hole transport process [23].

In the inverted structure of OSCs, silver is used as a hole collecting electrode because of its high work function characteristics. For electron transport layer (ETL) n-type metal oxides (such as $\mathrm{SnO}_{2}, \mathrm{TiO}_{2}$ and $\mathrm{ZnO}$ ) are used widely as ETL [24]-[26]. Among the meatal oxides, ZnO has high electron mobility, good transparency, availability, non-toxicity, and hole-blocking properties that make it a good ETL [27]. In organic/polymer based solar cells, dye sensitized solar cells, and perovskite based solar cells pure $\mathrm{ZnO}$ has been used as well [27]-[29]. Recently, metal doped n-type buffer layers have been studied by several research groups in order to increase the device performance of inverted solar cells. To improve the optical and electrical properties of $\mathrm{ZnO}$ layers metal doping is very efficient [30]. Good n-type dopant atoms can replace the $\mathrm{Zn}$ sites in the $\mathrm{ZnO}$ crystal and generate free electrons [31]-[36].

We fabricated an inverted solar cell with the structure of ITO/ZnO/ $\mathrm{P}_{3} \mathrm{HT}: \mathrm{PC}_{61} \mathrm{BM} / \mathrm{MoO}_{\mathrm{x}} / \mathrm{Ag} / \mathrm{Al}$. The device structure is shown in Figure 1. For OSC, the layers of ITO/PEDOT:PSS act as anode and Al acts as cathode, however for inverted organic solar cell (IOSC), the layers of YZO/ITO and Al play the roles of cathode and anode, respectively. Meanwhile, the layers of $\mathrm{YZO} / \mathrm{AgOx}$ and $\mathrm{MoOx}$ are chosen for electron and hole transport layers. The P3HT:PCBM is the active layer and the incident light enters devices from glass in both structures.

A blend of regioregular poly (3-hexylthiophene) (P3HT) and the fullerence derivative [6,6]-phenyl-C61 butyric acid methyl ester (PCBM) is used. The BHJ offers a large interfacial area for efficient excition dissociation. YZO is used as the anode contact. The effect of $\mathrm{ZnO}$ processing temperature on the photovoltaic properties of inverted solar cells is also described. Although higher temperatures leads to improvement in thin film crystallinity and electron mobility, annealed $\mathrm{ZnO}$ layers at $150^{\circ} \mathrm{C}$ showed best device performance [37]. To enhance the 


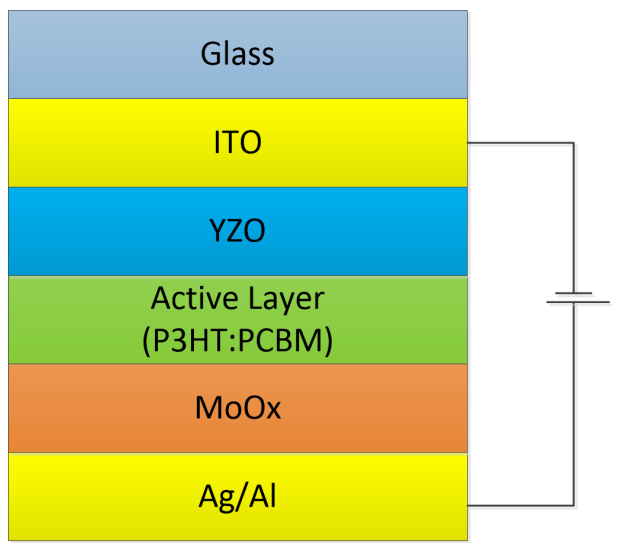

(a)

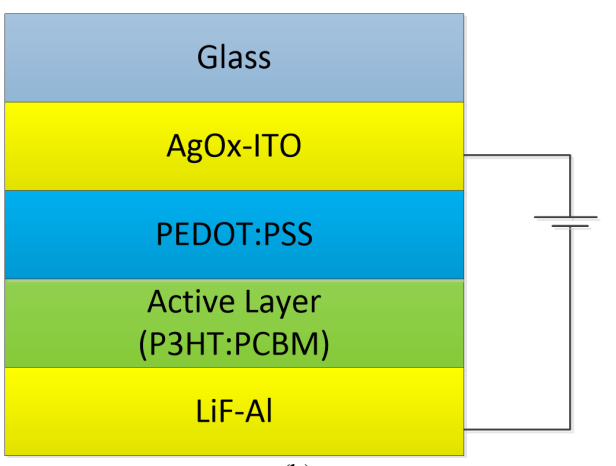

(b)

Figure 1. Schematic illustration of the IOSC with a structure of ITO/YZO/P3HT:PCBM/MoOx/Al (a), and conventional OSC with a structure of $\mathrm{AgO}_{x}$-ITO/PEDOT:PSS/P3HT:PCBM/LiF-Al (b).

electron transport properties in the $\mathrm{ZnO}$ films the effect of yttrium as a doping impurity was investigated. High efficiency organic solar cells were fabricated by doping yttrium in the $\mathrm{ZnO}$ electron transport layer and utilizing the optimized annealing conditions.

\section{Experimental Details}

\subsection{Zinc Oxide and Yttrium-Doped Zinc Oxide Precursor Solution}

N,N-dimethylformamide (99.8\%, Sigma-Aldrich) (MEA) $0.5 \mathrm{M}$ zinc acetate dihydrate $\left(\left(\mathrm{Zn}\left(\mathrm{CH}_{3} \mathrm{CO}_{2}\right)_{2} \cdot 2 \mathrm{H}_{2} \mathrm{O}\right)\right.$ was dissolved with monoethanolamine as chelating agent (stabilizer) to prepare $\mathrm{ZnO}$ and yttrium doped $\mathrm{ZnO}$ precursor solution. Until the mixture solution changed to a clear transparent solution, it was stirred on a hot plate at $60^{\circ} \mathrm{C}$ for about $1 \mathrm{hr}$ after adding $\mathrm{YCl}_{3} \cdot 6 \mathrm{H}_{2} \mathrm{O}$ in different amounts. All solutions were allowed to age for a day.

\subsection{Device Fabrication}

All devices were fabricated utilizing $40 \Omega-\mathrm{sq}^{-1}$ patterned ITO coated glass substrates. Prior to device fabrication the electrodes were cleaned in ultrasonic baths of methanol, acetone and isopropanol respectively. This was followed by a 15 min ultraviolet ozone (UVO) treatment. On cleaned patterned ITO substrate the ZnO/YZO precursor solution was spin coated at $3000 \mathrm{rpm}$ for $60 \mathrm{~s}$. In order to convert the precursor materials into $\mathrm{ZnO}$, heat treatments were given to solutions at various temperatures for an hour. To remove any organic residues that might be present on the surface, an ultraviolet ozone (UVO) treatment for 2 min was performed on the $\mathrm{ZnO} / \mathrm{YZO}$ layers. P3HT:PC61BM blends were dissolved in 1,2-dichlorobenzene (DCB) in 1:1 weight ratio. Then blend of P3HT:PC61BM was spin-coated at $600 \mathrm{rpm}$ for $1 \mathrm{~min}$. The photoactive layer was then dried at $150^{\circ} \mathrm{C}$ for $15 \mathrm{~min}$. Finally, a structure of $\mathrm{MoOx}(10 \mathrm{~nm}) / \mathrm{Ag}(10 \mathrm{~nm}) / \mathrm{Al}(70 \mathrm{~nm})$ was deposited by thermal evaporation in vacuum.

\subsection{Device Characterization}

Using a xenon-lamp solar simulator (Spectra Physics, Oriel Instruments, USA) Current density-voltage (J-V) measurements were performed. Simulated AM 1.5 global solar irradiation $\left(100 \mathrm{~mW} / \mathrm{cm}^{2}\right)$ was used for the measurement. Prior to the measurement the light source was calibrated with a standard Si photodiode reference cell (Hamamatsu Photonics, Japan).

\section{Results and Discussion}

\subsection{Annealing Temperature Effect on ZnO Thin Films and Corresponding Solar Cell Performance}

In the inverted structure, electrons get transferred to the ITO/ZnO from PC61BM, and holes travels towards to the MoOx/Ag/Al anode from P3HT. Organic stabilizers monoethanolamine (MEA) which was used during ZnO 
film formation, was removed by a short UVO treatment before the deposition of the active layer (P3HT: PC61BM). The removal of the stabilizer results in increased electronic contact between the ETL and the active layer improving the solar cell efficiency [38]-[40]. The oxygen atom vacancies are filled by prolonged UVO treatment which reduces the number of free electrons in the conduction band, which has an adverse effect on the device performance [41].

Table 1 shows the data for the inverted solar cell devices fabricated at different temperatures using solution processed and annealed $\mathrm{ZnO}$ layers. The OSCs utilizing ZnO ETL annealed at $50^{\circ} \mathrm{C}$ exhibited a PCE of $1.3 \%$ with a $V_{O C}$ of $0.6 \mathrm{~V}$, a $I_{S C}$ of $1.6 \mathrm{~mA}$, FF of $27.8 \%$. The OSCs fabricated with $\mathrm{ZnO}$ layers annealed at $150^{\circ} \mathrm{C}$ showed significant improvement in the PCE by $\sim 70 \%$ to $2.2 \%\left(V_{O C}=0.60 \mathrm{~V}, I_{S C}=1.7 \mathrm{~mA}\right.$, and FF $\left.=41.7 \%\right)$. However for higher temperature anneals of ZnO layers, there was a continuous depreciation of the PCE.

The parameters $R_{S H}$ and $R_{S}$ are two important parameters to explain the device characteristics of the solar cells. For ideal case the series resistance is close to zero and the shunt resistance should approach a large value. Based on the data, a hypothesis is made that heat treatment can modify the surface properties of the ZnO layer. When the $\mathrm{ZnO}$ layer was annealed temperature ranging from $50^{\circ} \mathrm{C}$ to $150^{\circ} \mathrm{C}$, the value of $R_{S}$ of the device decreases and the PCE increased. However, a further increase of the annealing temperature decreases the value of $R_{S H}$. This happens due to the higher leakage current resulted from higher surface roughness of ZnO ETLs. Table 1 reveals that excessive annealing of the $\mathrm{ZnO}$ layer deteriorates the device performance.

Both the donor/acceptor (D/A) and electrode/photovoltaic (E/P) interface plays important role in developing high-efficiency organic solar cells. The D/A interface is accountable for charge recombination, along with charge dissociation. And the E/P interface is responsible for charge collection to reduce the charge accumulation in generating photocurrent. The conductivity of specific charge carrier is represented by series resistance and the shunt resistance is due to the recombination of charge carriers at the D/A interface.

In organic solar cell structures smooth surface facilitate a uniform interfacial contact between the ETLs and active layers. This leads to an increase of the electron collection efficiency. Inspection of the samples after $150^{\circ} \mathrm{C}$ and $450^{\circ} \mathrm{C}$ anneals, divulges that the $\mathrm{ZnO}$ layer annealed at $450^{\circ} \mathrm{C}$ is comparatively rougher. It has a root-mean square $(\mathrm{rms})$ roughness value of $5.7 \mathrm{~nm}$. The $\mathrm{ZnO}$ film that is annealed at $150^{\circ} \mathrm{C}$ has an rms roughness value of $2.2 \mathrm{~nm}$.

\subsection{Effect of Yttrium Doping of ZnO Thin Films on the Efficiency of OSCs}

Previous studies showed that doping with yttrium ions decreases the resistivity of $\mathrm{ZnO}$ films; however, excessive doping leads to an increase in the resistivity of the films [42]. Donor $\mathrm{Y}^{3+}$ ions substitute onto $\mathrm{Zn}^{2+}$ lattice sites at low doping concentrations. This results in an increased number of charged carriers and provides the initial reduction in resistivity. However the dopant concentration is increased to higher levels, the increased impurity - scattering from the dopant ions dominates and the resistivity starts to rise. Hence, different concentrations of the $\mathrm{Y}^{3+}$ are added to the zinc oxide precursor solution and spin coated on top of ITO layer to observe the effects of doping. Figure 2 shows the UV-Vis absorption spectra of various YZO thin films. It is also clear from the figure that the transmittance spectra have no significant difference regardless of the amount of yttrium added. In the visible region all the films have good optical transmittance. YZO films are very thin and could be considered as completely transparent which could be the reason behind this.

\section{Equivalent Circuit Diagram}

Most of the solar cells are semiconductors with a p-n junction fabricated in a thin wafer or layer of semiconductors. When solar cells are exposed to light electron-hole pairs are generated which results in the generation of

Table 1. Device parameters of $\mathrm{ZnO}$ based inverted organic solar cells under illumination (average of five devices).

\begin{tabular}{ccccc}
\hline ZnO Anneal Temperature & $50^{\circ} \mathrm{C}$ & $150^{\circ} \mathrm{C}$ & $300^{\circ} \mathrm{C}$ & $450^{\circ} \mathrm{C}$ \\
\hline$V_{O C}(\mathrm{~V})$ & 0.6 & 0.6 & 0.6 & 0.5 \\
$I_{S C}(\mathrm{~mA})$ & 1.6 & 1.7 & 1.8 & 1.3 \\
$\mathrm{FF}(\%)$ & 27.8 & 41.7 & 32.9 & 31.4 \\
$R_{S H}\left(\Omega \cdot \mathrm{cm}^{2}\right)$ & 130 & 510 & 150 & 92 \\
$R_{S}\left(\Omega \cdot \mathrm{cm}^{2}\right)$ & 39 & 13 & 28 & 9 \\
PCE (\%) & 1.3 & 2.2 & 1.7 & 1.0 \\
\hline
\end{tabular}


photo current In the dark the I-V characteristic of a solar cell have an exponential characteristic similar to that of a diode. The terminal current $I_{D}$ of an idealized diode without resistance may be described in mathematical terms by Shockley's equation:

$$
I_{D}=I_{0}\left[\exp \left(\frac{V}{n k T / q}\right)-1\right]
$$

where, $V$ is the terminal voltage, $I_{0}$ is the reverse current, $n$ is the so-called diode quality factor, $k$ is Boltzmann's constant, $T$ is temperature, and $q$ is the charge of an electron. Figure 3 represents the equivalent circuit model of a diode with parasitic series resistance. The terminal current of the equivalent circuit is given by the following equation:

$$
I=I_{0}\left[\exp \left(\frac{V+I R s}{n k T / q}\right)-1\right] .
$$

The simplest model to understand the characteristics of organic solar cells is the single diode model. Figure 4

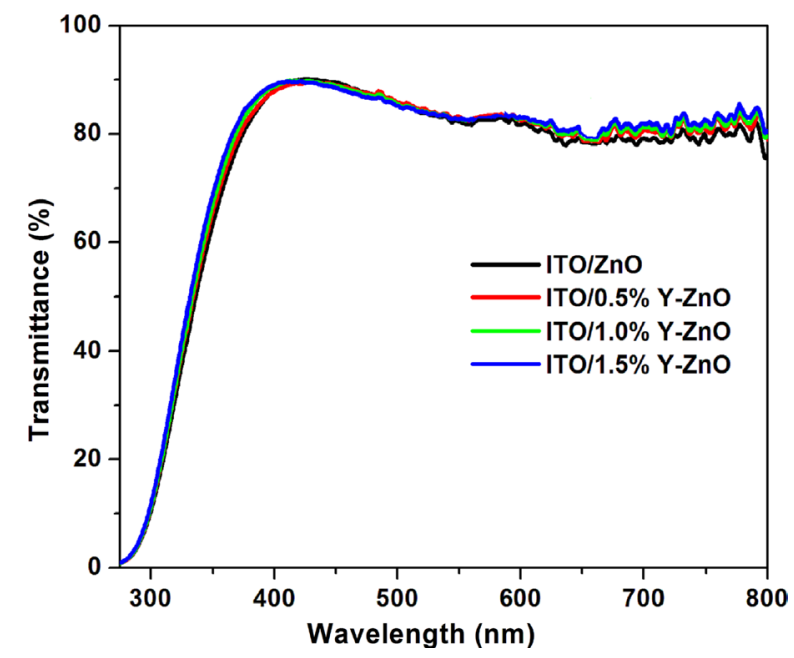

Figure 2. Optical transmission spectra of sol-gel prepared zinc oxide and yttrium doped zinc oxide layers on ITO coated glass substrates.

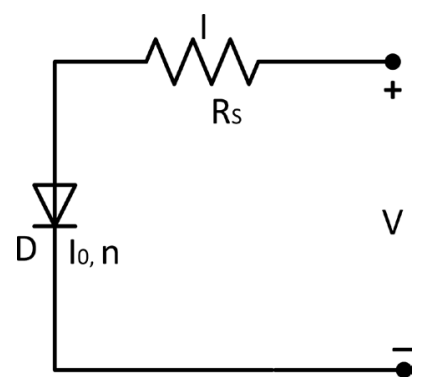

Figure 3. Equivalent circuit model of a single diode with a parasitic series resistance.

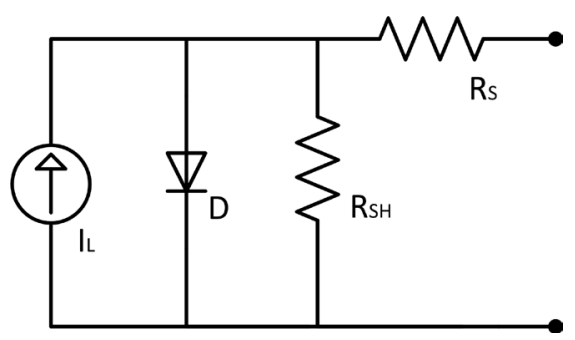

Figure 4. The equivalent circuit diagram of single diode model. 
shows the equivalent circuit diagram of a single diode model with series resistance and shunt resistance. The generation of current upon illumination is represented by the current source. The built in field due to the difference between the donor HOMO and acceptor LUMO level creates and asymmetry of conductivity which is represented by a voltage dependent resistor or the ideal diode $\mathrm{D}$.

Using the Shockley diode characteristics equations mentioned above in Equation (1). The voltage dependence of current can be given by Equation (3), where $I_{L}$ is the photo current.

$$
I=\left(I_{L}-\frac{V}{R_{S H}}\right) \frac{R_{S H}}{R_{S H}+R_{S}}-I_{0}\left[\exp \left(\frac{V+I R_{S}}{n k T / q}\right)-1\right] \cdot \frac{R_{S H}}{R_{S H}+R_{S}} .
$$

While the diode $\mathrm{D}$ is in the dark so that $R_{S H}=\infty, R_{S}=0$, then from Equation (3) we get Equation (1). The open circuit voltage is obtained setting the output current zero $(I=0)$, and is given by Equation (4)

$$
V_{O C}=\frac{n k T}{q} \ln \left(\frac{I_{L}-V_{O C} / R_{S H}}{I_{0}}+1\right) .
$$

In previous studies a two diode model consisting of an extra diode showed more accurate results in describing the characteristics of the organic solar cells. The equivalent circuit of the two diode model is shown in Figure 5. Holes at the ITO electrode from an extra blocking contact that can affect the IV cure in the third quadrant. The second diode represents the effect of this blocking contact. Using the Shockley diode equations we obtain:

$$
I=\left(I_{L}-\frac{V}{R_{S H}}\right) \frac{R_{S H}}{R_{S H}+R_{S}}-I_{01}\left[\exp \left(\frac{V+I R_{S}}{n k T / q}\right)-1\right] \frac{R_{S H}}{R_{S H}+R_{S}}-I_{02}\left[\exp \left(\frac{V+I R_{S}}{n k T / q}\right)-1\right] \frac{R_{S H}}{R_{S H}+R_{S}} .
$$

Setting $I=0$ we get the equation for $V_{O C}$ which is

$$
V_{\text {OC }}=\frac{n k T}{q} \ln \left(\frac{I_{L}-V_{O C} / R_{S H}}{I_{01}-I_{02}}+1\right) .
$$

In a previous study, we proposed a two diode model with an extra resistance connected in series with the diode based on the device behavior with the change of series and shunt resistance [23]. We used the model to describe the electrical characteristics of PCBM and P3HT based organic solar cell with an added interfacial layer of AgOx in between PEDOT:PSS and ITO. Figure 6 is used to describe the electrical characteristics.

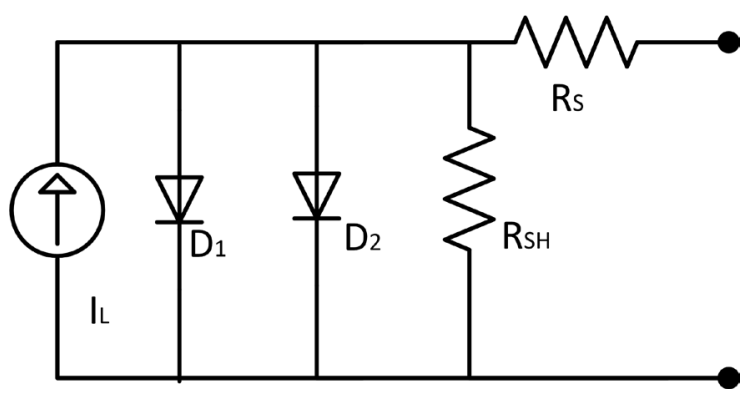

Figure 5. The equivalent circuit diagram of two diode model.

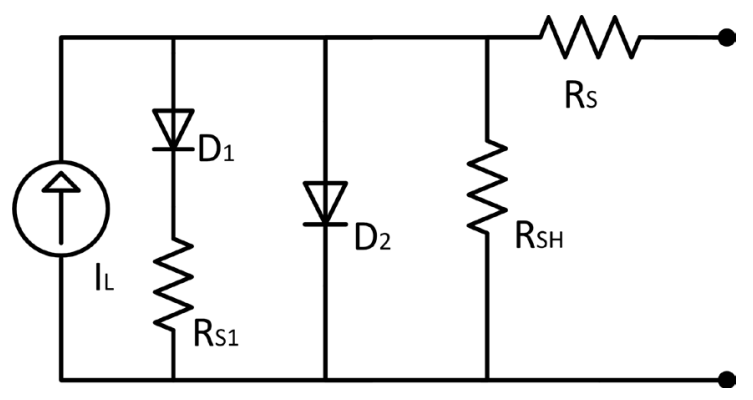

Figure 6. Proposed equivalent circuit model for the inverted organic solar cell. 
In this proposed model, the shunt resistance in series the diode $\mathrm{D}_{1}$ represents the shorts due to significant conductivity of the bulk material and the pinholes. The recombination losses near the electrodes may also be accounted by this resistor. If $R_{S}$ is considerably smaller than both of the shunt resistance, the effect of $R_{S 1}$ can be considered with $R_{S H}$. The shape of FF and $V_{O C}$ of the I-V curve virtually remains unchanged for very high value of $R_{S H}$. And for negative bias the current has significant field dependency. However, smaller values of $R_{S H}$ reduce $V_{O C}$ and the FF reaches its theoretical minimum.

The main difference between the conventional and inverted organic solar cells is there device structure. The both exhibits same type of electrical characteristics. And both the D/A and E/P interface have critical effect on their efficiency. Based on our experimental results we used the above model to explain the electrical characteristic of the inverted organic solar cell. The I-V characteristics curve from simulation and experimental data is shown in Figure 7. In Figure 8, the I-V characteristics curve for 1.0\% at. Y-doped $\mathrm{ZnO}$ is shown along with the proposed model and other previously discussed models. Figure 8 shows that proper correlation is achieved between the experimental and simulated I-V plots. And it is clear from Figure 8 that our previous proposed model can successfully describe the electrical characteristics of Y-doped ZnO inverted solar cells. Table 2 shows the data for inverted organic solar cells fabricated at different concentration of yttrium, using solution

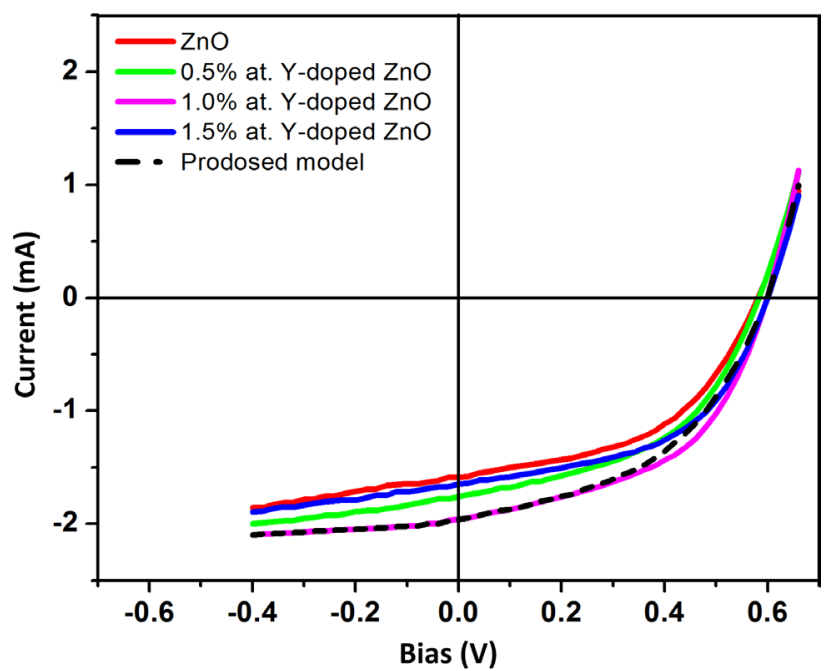

Figure 7. Current-voltage (I-V) characteristics of the $\mathrm{ZnO}$ and $\mathrm{Y}$ doped $\mathrm{ZnO}$ based OPV devices under $100 \mathrm{~mW} / \mathrm{cm}^{2}$ illumination (device area is $0.2 \mathrm{~cm}^{2}$ ).

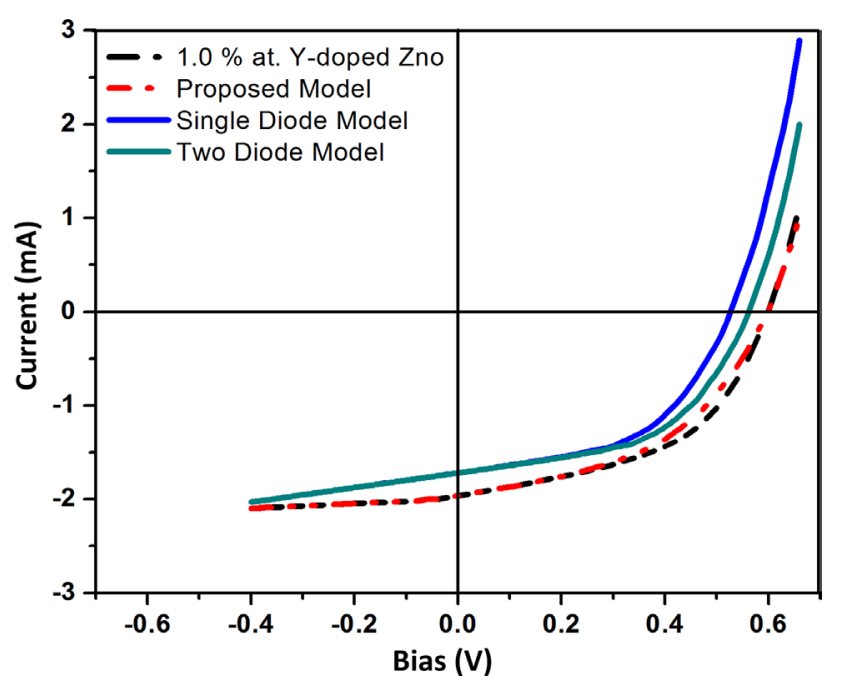

Figure 8. Current-voltage (I-V) characteristics for $1 \%$ at Y-doped $\mathrm{ZnO}$ based OPV device and different equivalent circuit models under $100 \mathrm{~mW} / \mathrm{cm}^{2}$ illumination (device area is $0.2 \mathrm{~cm}^{2}$ ). 
Table 2. Device parameters of $\mathrm{ZnO}$ based inverted organic solar cells under illumination (average of five devices).

\begin{tabular}{ccccc}
\hline ETL & ZnO & $0.5 \%$ YZO & $1.0 \%$ YZO & $1.5 \%$ YZO \\
$V_{O C}(\mathrm{~V})$ & 0.6 & 0.6 & 0.6 & 0.6 \\
$I_{S C}(\mathrm{~mA})$ & 1.6 & 1.8 & 2.0 & 1.8 \\
FF $(\%)$ & 41.7 & 49.2 & 49.3 & 51.5 \\
$R_{S H}\left(\Omega \cdot \mathrm{cm}^{2}\right)$ & 510 & 283 & 254 & 334 \\
$R_{S}\left(\Omega \cdot \mathrm{cm}^{2}\right)$ & 13 & 7 & 6 & 9 \\
PCE $(\%)$ & 2.2 & 2.7 & 2.9 & 2.7 \\
\hline
\end{tabular}

processed and annealed $\mathrm{ZnO}$ layers.

The efficiency of the inverted organic solar cell fabricated with 1.0 at. \% Y-doped ZnO exhibited the best photovoltaic performance among all the devices, with PCE of $2.9 \%$, I of $2 \mathrm{~mA}-\mathrm{cm}^{-2}, V_{O C}$ of $0.6 \mathrm{~V}$ and FF of $49.3 \%$. There was only $1.2 \%$ variation between the simulated and experimental I-V plots.

\section{Conclusion}

In this work we shown, the performance of ZnO ETLs in P3HT:PCBM inverted solar cell structure with optimized annealing conditions. It was found that for sol-gel processed $\mathrm{ZnO}$ annealing condition, the $\mathrm{ZnO}$ layer played a dominant role in determining the solar cell device performance. Further our work reports that yttrium doping into $\mathrm{ZnO}$ can improve the PCE of organic solar cells even more. Yttrium into zinc oxide layer resulted in a 30\% improvement of PCE. Lastly, an equivalent circuit diagram was proposed to explain the characteristics of the device. A comparison between the experimental and simulated I-V curve was also shown. It was reported that this device correlates with the proposed equivalent circuit model from our previous study.

\section{Acknowledgements}

This research was partially supported by the National Science Foundation (C. Ying, Grant No. DMR-0902277).

\section{References}

[1] Hassan, H.Z., Mohamad, A.A. and Al-Ansary, H.A. (2012) Development of a Continuously Operating Solar-Driven Adsorption Cooling System: Thermodynamic Analysis and Parametric Study. Applied Thermal Engineering, 48, 332-341. http://dx.doi.org/10.1016/j.applthermaleng.2012.04.040

[2] Hassan, H.Z. and Mohamad, A.A. (2012) A Review on Solar-Powered Closed Physisorption Cooling Systems. Renewable and Sustainable Energy Reviews, 16, 2516-2538. http://dx.doi.org/10.1016/j.rser.2012.02.068

[3] Afshar, O., et al. (2012) A Review of Thermodynamics and Heat Transfer in Solar Refrigeration System. Renewable and Sustainable Energy Reviews, 16, 5639-5648. http://dx.doi.org/10.1016/j.rser.2012.05.016

[4] (2015) Exposed: U.N. Intergovernmental Panel On Climate Change IPCC. Retrieved July 8.

[5] Tsuzuki, T., Shirota, Y., Rostalski, J. and Meissner, D. (2000) The Effect of Fullerene Doping on Photoelectric Conversion Using Titanyl Phthalocyanine and a Perylene Pigment. Solar Energy Materials and Solar Cells, 1-8.

[6] Li, Z.F. and Sumathy, K. (2000) Technology Development in the Solar Absorption Air-Conditioning Systems. Renewable and Sustainable Energy Reviews, 4, 267-293. http://dx.doi.org/10.1016/S1364-0321(99)00016-7

[7] Brabec, C.J., Sariciftci, N.S. and Hummelen, C. (2001) Plastic Solar Cells. Advanced Functional Materials, 11, 15-26. http://dx.doi.org/10.1002/1616-3028(200102)11:1<15::AID-ADFM15>3.0.CO;2-A

[8] Spanggaard, H. and Krebs, F.C. (2004) A Brief History of the Development of Organic and Polymeric Photovoltaics. Solar Energy Materials and Solar Cells, 83, 125-146. http://dx.doi.org/10.1016/j.solmat.2004.02.021

[9] Hoppe, H. and Sariciftci, N.S. (2004) Organic Solar Cells: An Overview. Journal of Materials Research, 19, 19241945. http://dx.doi.org/10.1557/JMR.2004.0252

[10] Dang, M.T., Hirsch, L. and Wantz, G. (2011) P3HT:PCBM, Best Seller in Polymer Photovoltaic Research. Advanced Materials, 23, 3597-3602. http://dx.doi.org/10.1002/adma.201100792

[11] Guo, S., Brandt, C., Andreev, T., Metwalli, E., Wang, W., Pelich, J. and Muller-Buschbaum, P. (2014) First Step into Space: Performance and Morphological Evolution of P3HT:PCBM Bulk Heterojunction Solar Cells under AM0 Illumination. ACS Applied Materials \& Interfaces, 6, 17902-17910. http://dx.doi.org/10.1021/am504608p 
[12] Schaffer, C.J., Palumbiny, C.M., Niedermeier, M.A., Jendrzejewski, C., Santoro, G., Roth, S.V. and Muller-Buschbaum, P. (2013) A Direct Evidence of Morphological Degradation on a Nanometer Scale in Polymer Solar cells. Advanced Materials, 25, 6760-6764. http://dx.doi.org/10.1002/adma.201302854

[13] Vongsaysy, U., Bassani, D.M., Servant, L., Pavageau, B., Wantz, G. and Aziz, H. (2014) Formulation Strategies for Optimizing the Morphology of Polymeric Bulk Heterojunction Organic Solar Cells: A Brief Review. Journal of Photonics for Energy, 4, Article ID: 040998. http://dx.doi.org/10.1117/1.JPE.4.040998

[14] Dutta, P., Xie, Y., Kumar, M., Rathi, M., Ahrenkiel, P., Galipeau, D., Qiao, Q. and Bommisetty, V. (2011) Connecting Physical Properties of Spin-Casting Solvents with Morphology, Nanoscale Charge Transport, and Device Performance of Poly(3-hexylthiophene): Phenyl-C61-Butyric Acid Methyl Ester Bulk Heterojunction Solar Cells. Journal of Photonics for Energy, 1, Article ID: 011124. http://dx.doi.org/10.1117/1.3662467

[15] Vongsaysy, U., Pavageau, B., Wantz, G., Bassani, D.M., Servant, L. and Aziz, H. (2014) Guiding the Selection of Processing Additives for Increasing the Efficiencies of Bulk Heterojunction Polymeric Solar Cells. Advanced Energy Materials, 4, 1300752-1300760. http://dx.doi.org/10.1002/aenm.201300752

[16] Jorgensen, M., Normann, K. and Krebs, F.C. (2008) Stability/Degradation of Polymer Solar Cells. Solar Energy Materials and Solar Cells, 92, 686-714. http://dx.doi.org/10.1016/j.solmat.2008.01.005

[17] Steim, R., Kogler, F.R. and Brabec, C.J. (2010) Interface Materials for Organic Solar Cells. Journal of Materials Chemistry, 20, 2499-2512. http://dx.doi.org/10.1039/b921624c

[18] Xin, H., Subramaniyan, S., Kwon, T.-W., Shoaee, S., Durrant, J.R. and Jenekhe, S.A. (2012) Enhanced Open Circuit Voltage and Efficiency of Donor-Acceptor Copolymer Solar Cells by Using Indene-C60 Bisadduct. Chemistry of Materials, 24, 1995-2001. http://dx.doi.org/10.1021/cm300355e

[19] Chen, H.-Y., Hou, J., Zhang, S., Liang, Y., Yang, G., Yang, Y., Yu, L., Wu, Y. and Li, G. (2009) Polymer Solar Cells with Enhanced Open-Circuit Voltage and Efficiency. Nature Photonics, 3, 649-653. http://dx.doi.org/10.1038/nphoton.2009.192

[20] Lee, J.-Y., Kim, S.-H., Song, I.-S. and Moon, D.-K. (2011) Efficient Donor-Acceptor Type Polymer Semiconductors with Well-Balanced Energy Levels and Enhanced Open Circuit Voltage Properties for Use in Organic Photovoltaics. Journal of Materials Chemistry, 21, 16480-16487. http://dx.doi.org/10.1039/c1jm12145f

[21] Ma, H., Yip, H.-L., Huang, F. and Jen, A.K.-Y. (2010) Interface Engineering for Organic Electronics. Advanced Functional Materials, 20, 1371-1388. http://dx.doi.org/10.1002/adfm.200902236

[22] Chen, L.-M., Xu, Z., Hong, Z. and Yang, Y. (2010) Interface Investigation and Engineering-Achieving High Performance Polymer Photovoltaic Devices. Journal of Materials Chemistry, 20, 2575-2598. http://dx.doi.org/10.1039/b925382c

[23] Hossain, N, Das, S. and Alford, T.L. (2015) Equivalent Circuit Modification for Organic Solar Cells. Circuits and Systems, 6, 153-160. http://dx.doi.org/10.4236/cs.2015.66016

[24] Bob, B., Song, T.-B., Chen, C.-C., Xu, Z. and Yang, Y. (2013) Nanoscale Dispersions of Gelled SnO 2 : Material Properties and Device Applications. Chemistry of Materials, 25, 4725-4730. http://dx.doi.org/10.1021/cm402462m

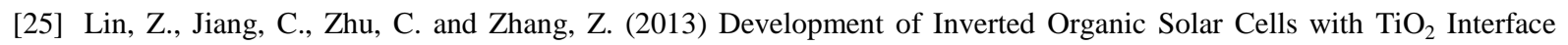
Layer by Using Low-Temperature Atomic Layer Deposition. ACS Applied Materials \& Interfaces, 5, 713-718. http://dx.doi.org/10.1021/am302252p

[26] Sun, Y., Seo, J.H., Takacs, C.J., Seifter, J. and Heeger, A.J. (2011) Inverted Polymer Solar Cells Integrated with a Low-Temperature-Annealed Sol-Gel Derived ZnO Film as an Electron Transport Layer. Advanced Materials, 23, 1679-1683. http://dx.doi.org/10.1002/adma.201004301

[27] Ka, Y., Lee, E., Park, S.Y., Seo, J., Kwon, D.-G., Lee, H.H., Park, Y., Kim, Y.S. and Kim, C. (2013) Effect of Annealing Temperature of Aqueous Solution-Processed ZnO Electron-Selective Layers on Inverted Polymer Solar Cells. Organic Electronics, 14, 100-104. http://dx.doi.org/10.1016/j.orgel.2012.10.013

[28] Liu, D. and Kelly, T.L. (2014) Perovskite Solar Cells with a Planar Heterojunction Structure Prepared Using RoomTemperature Solution Processing Techniques. Nature Photonics, 8, 133-138. http://dx.doi.org/10.1038/nphoton.2013.342

[29] Sarkar, K., Braden, E.V., Pogorzalek, S., Yu, S., Roth, S.V. and Muller-Buschbaum, P. (2014) Monitoring Structural Dynamics of in Situ Spray-Deposited Zinc Oxide Films for Application in Dye-Sensitized Solar Cells. ChemSusChem, 7, 2140-2147. http://dx.doi.org/10.1002/cssc.201402049

[30] Minami, T. (2005) Transparent Conducting Oxide Semiconductors for Transparent Electrodes. Semiconductor Science and Technology, 20, S35-S44. http://dx.doi.org/10.1088/0268-1242/20/4/004

[31] Minami, T., Nanto, H. and Takata, S. (1984) Highly Conductive and Transparent Aluminum Doped Zinc Oxide Thin Films Prepared by RF Magnetron Sputtering. Japanese Journal of Applied Physics, 23, L280-L282. http://dx.doi.org/10.1143/JJAP.23.L280 
[32] Cheng, Y., Cao, L., He, G., Yao, G., Song, X. and Sun, Z. (2014) Preparation, Microstructure and Photoelectrical Properties of Tantalum-Doped Zinc Oxide Transparent Conducting Films. Journal of Alloys and Compounds, 608, 8589. http://dx.doi.org/10.1016/j.jallcom.2014.03.031

[33] Major, S. and Chopra, K.L. (1988) Indium Doped Zinc Oxide Films as Transparent Electrodes for Solar Cells. Solar Energy Materials, 17, 319-327. http://dx.doi.org/10.1016/0165-1633(88)90014-7

[34] Kaur, R., Singh, A.V. and Mehra, R.A. (2005) Structural, Electrical and Optical Properties of Sol-Gel Derived Yttrium Doped ZnO Films. Physica Status Solidi (A), 202, 1053-1059. http://dx.doi.org/10.1002/pssa.200420006

[35] Chandra, R.D., Rao, M., Zhang, K., Prabhakar, R.R., Shi, C., Zhang, J., Mhaisalkar, S.G. and Mathews, N. (2014) Tuning Electrical Properties in Amorphous Zinc Tin Oxide Thin Films for Solution Processed Electronics. ACS Applied Materials \& Interfaces, 6, 773-777. http://dx.doi.org/10.1021/am401003k

[36] Minami, T., Sato, H., Nanto, H. and Takata, S. (1985) Group III Impurity Doped Zinc Oxide Thin Films Prepared by RF Magnetron Sputtering. Japanese Journal of Applied Physics, 24, L781-L784. http://dx.doi.org/10.1143/JJAP.24.L781

[37] Lee, J.-H., Ko, K.-H. and Park, B.-O. (2003) Electrical and Optical Properties of ZnO Transparent Conducting Films by the Sol-Gel Method. Journal of Crystal Growth, 247, 119-125. http://dx.doi.org/10.1016/S0022-0248(02)01907-3

[38] Cho, J.M., Kwak, S.-W., Aqoma, H., Kim, J.W., Shin, W.S., Moon, S.-J., Jang, S.-Y. and Jo, J. (2014) Effects of Ultraviolet-Ozone Treatment on Organic-Stabilized ZnO Nanoparticle-Based Electron Transporting Layers in Inverted Polymer Solar Cells. Organic Electronics, 15, 1942-1950. http://dx.doi.org/10.1016/j.orgel.2014.05.016

[39] Kato, Y., Jung, M.-C., Lee, M.V. and Qi, Y. (2014) Electrical and Optical Properties of Transparent Flexible Electrodes: Effects of UV Ozone and Oxygen Plasma Treatments. Organic Electronics, 15, 721-728. http://dx.doi.org/10.1016/j.orgel.2014.01.002

[40] Ip, K., Gila, B.P., Onstine, A.H., Lambers, E.S., Heo, Y.W., Baik, K.H., Norton, D.P., Pearton, S.J., Kim, S., LaRoche, J.R. and Ren, F. (2004) Improved Pt/Au and W/Pt/Au Schottky Contacts on $n$-Type ZnO Using Ozone Cleaning. Applied Physics Letters, 84, 5133-5135. http://dx.doi.org/10.1063/1.1764940

[41] Bao, Q., Liu, X., Xia, Y., Gao, F., Kauffmann, L.-D., Margeat, O., Ackermann, J. and Fahlman, M. (2014) Effects of Ultraviolet Soaking on Surface Electronic Structures of Solution Processed ZnO Nanoparticle Films in Polymer Solar Cells. Journal of Materials Chemistry A, 2, 17676-17682. http://dx.doi.org/10.1039/C4TA02695K

[42] X. Han, Han, K. and Tao, M. (2010) Low Resistivity Yttrium-Doped Zinc Oxide by Electrochemical Deposition. Journal of the Electrochemical Society. 157, H593-H597. http://dx.doi.org/10.1149/1.3377092 